\title{
VALIDATION OF MATRIX MATCHED CALIBRATION FOR ANALYSIS OF INSECTICIDE AND FUNGICID RESIDUES IN CUCUMBER AND TOMATO USING QUEChERS SAMPLE PREPARATION FOLLOWED BY GAS CHROMATOGRAPHY-MASS SPECTROMETRY
}

\author{
ZAHRA DASHTBOZORGI, ${ }^{* 1}$ MOHAMMAD KAZEM RAMEZANI, ${ }^{2}$ SYED WAQIF HUSAIN, ${ }^{1}$ \\ PARVIZ ABRUMAND-AZAR, ${ }^{1}$ AND MOHSEN MOROWATI ${ }^{2}$
}

\author{
${ }^{\prime}$ Department of Chemistry, Science and Research Branch, Islamic Azad University, Tehran, Iran. \\ ${ }^{2}$ Laboratory of Pesticide Residues Research, Pesticide Research Department, Iranian Research Institute of Plant Protection (IRIPP), Tehran, Iran.
}

(Received: July 19, 2012 - Accepted: February 23, 2013)

\begin{abstract}
A rapid, specific and sensitive multi-residue method based on the quick, east, cheap, effective, rugged and safe (QuEChERS) has been developed and validated for the determination of 19 multi-class insecticide and fungicide residues (Aldrin, Amitraz, Bromopropylate, Chlorpyrifos, DDT, Diazinon, Dichlorovos, Ethion, Fenpropathrin, Fenvalerate, Iprodion, Malathion, Metalaxyl, Oxydemethon methyl, Permethrin, Phosalone, Pirimicarb, Profenofos and Tetradifon) in greenhouse cucumber and tomato. Gas chromatography-mass spectrometric detection in selected ion monitoring mode (GC/MS-SIM) was applied for determination of pesticides residues. Quantification was performed using matrix-matched calibration and solvent calibration. Recovery studies were used for comparison of accuracy of each calibration method. Results showed matrix matched calibration would be efficient for quantification of pesticide residues in Iranian cucumber and tomato.
\end{abstract}

Keywords: QuEChERS, Pesticide residues, Matrix matched calibration, Insecticides, Fungicides, GC/MS-SIM

\section{INTRODUCTION}

The use of pesticides in fruit crops is essential to protect against pests and diseases (which may decrease the yield of production) as well as to improve the fruit and vegetable quality. Due to this pesticide residues may be present in fruits, vegetables, grains and other plant products.

Both cucumber and tomato (used fresh or processed and canned) are the most important and frequently grown vegetables in greenhouse, open fields and plastic sheds in Iran. During their growth, different pesticides are applied to control pests and diseases. Nowadays, public concern in pesticide residues in food and related products has been increased. Therefore, the rapid multiresidue determination of wide range of pesticides in many samples is needed. Multiresidue methods (MRMs) are very effective to meet the demand for pesticide residue analysis with low cost. ${ }^{1}$ Multiresidue method development is difficult, due to the fact that pesticides of different polarity, solubility and volatility have to be extracted and analyzed. In practice, a multiresidue method consists of three basic steps: (i) extraction, (ii) cleanup, and (iii) determination.

For extraction, the use of acetone, ${ }^{2}$ ethyl acetate (EtOAc), ${ }^{3-5}$ methanol ${ }^{6,7}$ and acetonitrile $(\mathrm{MeCN})^{8}$ has prevailed in MRMs. These solvents provide high pesticide recoveries over a wide polarity range. Nevertheless, at the same time a lot of matrix components are co-extracted. To achieve required performance features, cleanup techniques, such as gel permeation chromatography (GPC), ${ }^{9}$ solid-phase extraction (SPE), ${ }^{10}$ and/or liquid-liquid partitioning (LLP) ${ }^{11}$ are usually employed. These procedures lead to increasing overall cost of the method, extending analysis time and necessitating additional labour. A breakthrough in the field of sample preparation is the QuEChERS approach which stands for quick, easy, cheap, effective, rugged, and safe introduced by Anastassiades et al. ${ }^{12}$ and developed for the extraction of pesticides from fruits and vegetables. This method uses an acetonitrile extraction/partitioning and a dispersive solid phase extraction step for the cleanup. In comparison with other MRMs, this method has several benefits like high recoveries for a wide volatility range of pesticides, accurate results, quick treatment, reduced use of solvent and reagents. QuEChERS is extremely fast and inexpensive with great ruggedness, suitable for a wide range of pesticide residues in many different commodities including fruits and vegetables, ${ }^{13-21}$ rice, ${ }^{22}$ Soil, ${ }^{23}$ baby food, ${ }^{24}$ olives, ${ }^{25}$ milk, ${ }^{26,27}$ herbs ${ }^{27}$ and honey. ${ }^{28}$

In the determination step for pesticide residues, either gas chromatography (GC) and/or liquid chromatography (LC) are used in MRMs. Conventionally; selective detectors in GC have been used to detect individual classes of GC-amenable pesticides, such as organochlorines, organophosphates, and organonitrogens. ${ }^{29-34} \mathrm{GC}-\mathrm{MS}$ has become the principal approach to analyze all classes of GC-amenable pesticides in the same chromatogram. ${ }^{35-38}$ Traditionally, GC-MS was mainly applied for confirmation of analytes formerly detected by selective detectors, but modern GC-MS instruments are sensitive, easy to use, reliable, and affordable for most laboratories. GC-MS has become a standard laboratory instrument and can provide qualitative and quantitative information for basically any GC-amenable analyte in a single injection.

Numerous MS techniques are available, the most common of which use a quadrupole design that is very rugged and practical. Ion trap MS instruments provide the advantages of lower limit of quantification (LOQ) in full-scan operation and the option for conducting $\mathrm{MS}^{\mathrm{n}}$ of targeted analytes. Timeof-flight (TOF) instruments are more expensive, but may provide greater speed or higher mass resolution in the analysis. Magnetic sector is a fourth MS instrument option, but they are very large and expensive and generally restricted for special applications. Any of these MS techniques may be coupled with $\mathrm{GC}$ for pesticide residue analysis and produce equal high-quality results. 39,40

Many studies have been reported concerning the determination of pesticides using $\mathrm{GC}-\mathrm{MS}^{41-44}$ but this is the first attempt in Iran using gas chromatograph - mass spectrometric detection in selected ion monitoring mode (GC/MS-SIM) technique to determine pesticides of difference classes in two of the most important Iranian vegetables. The main aim of this study was to develop and validate an effective and reliable calibration method for determination of low level pesticide residues in Iranian tomato and cucumber. This objective was successfully met through matrix match calibration for QuEChERS sample preparatin method, including a simple simultaneous cleanup and concentration step, followed by determination using gas chromatography-mass spectrometric detection in selected ion monitoring mode (GC/MS-SIM).

\section{EXPERIMENTAL}

\section{Chemicals and instruments}

Acetonitrile (MeCN), HPLC grade, and Glacial acetic acid (AC), were purchased from Merck (Germany). Anhydrous magnesium sulphate $\left(\mathrm{MgSO}_{4}\right)$ and primary secondary amine (PSA) were prepared from Agilent technology, (USA). Anhydrous Sodium acetate $(\mathrm{NaAC})$ was attained from Merck (Germany). Pesticide reference standards were obtained from Dr. Ehrenstorfer (Augsburg, Germany), Sigma-Aldrich Chemie GmbH, Germany, and Chemservice (West Chester, PA). Thriphenyl phosphate (TPP) (SigmaAldrich Chemie GmbH, Germany) was used as internal standard (ISTD). Stock solutions of 1000-2000 $\mathrm{gmL}^{-1}$ were prepared in various solvents (methanol, $\mathrm{n}$-Hexane, Acetonitrile) and working standard pesticide mixtures of $0.05-10$ $\mu \mathrm{g} \mathrm{mL} \mathrm{L}^{-1}$ were prepared in $\mathrm{MeCN}$.

An Agilent $5975 \mathrm{C}$ gas chromatograph connected to Agilent 7890A mass-selective detector equipped with Agilent 7683 autosampler (Agilent technologies, USA) was employed for determination of pesticide residues in this study. The column used was a capillary column (HP-5, $30 \mathrm{~m} \times 0.25 \mathrm{~mm}$, $0.25 \mu \mathrm{m}, \mathrm{J} \& \mathrm{~W}$ Sci. USA) with the following conditions: He gas constant flow, $1 \mathrm{~mL} \mathrm{~min}{ }^{-1}$, inlet temperature $250{ }^{\circ} \mathrm{C}$, injection volume, $1 \mu \mathrm{L}$ (splitless), mass spectrometry transfer line temperature was $290{ }^{\circ} \mathrm{C}$, initial oven temperature, $60^{\circ} \mathrm{C}$, held for $3 \mathrm{~min}$, then a $6^{\circ} \mathrm{C} \mathrm{min}{ }^{-1}$ ramp to $100{ }^{\circ} \mathrm{C}$ followed by a $10^{\circ} \mathrm{C} \mathrm{min}^{-1}$ 
ramp to $160{ }^{\circ} \mathrm{C}$ and a $2{ }^{\circ} \mathrm{C} \mathrm{min}{ }^{-1}$ ramp to $260{ }^{\circ} \mathrm{C}$ and then a $30{ }^{\circ} \mathrm{C} \mathrm{min}-1$ ramp to $280{ }^{\circ} \mathrm{C}$ (held for $2 \mathrm{~min}$ ). The quadrupole was operated in SIM mode with EI, and the multiplier was set $200 \mathrm{~V}$ above the autotuned setting. A Heidolph (Germany) Vortex mixer was used to swirl the tubes before centrifuging. A Vision south VS-5000N Centrifuge (Korea) was used for sample preparation. An Eyela (Japan) instrument with nitrogen (Linde Gas, Poland) was used to evaporate the solvent, and concentrate the extracts.

QuEChERS sample preparation method

For cucumber and tomato we used QuEChERS methodology, which involved the following steps: (i) weighing $15 \mathrm{~g}$ of thoroughly homogenized sample into a $50 \mathrm{~mL}$ fluoroethylene propylene (FEP) centrifugation tube, (ii) adding $15 \mathrm{~mL} \mathrm{MeCN} \mathrm{(10 \%} \mathrm{AC),} \mathrm{(iii)} 6 \mathrm{~g}$ anh. MgSO4 and $1 \mathrm{~g} \mathrm{NaAC}$ was added, (iv) shaken vigorously for $1 \mathrm{~min}$ by hand, and (v) centrifuge the tube at $3450 \mathrm{rcf}$ (relative centrifugal force) for $5 \mathrm{~min}$. Then a dispersive- SPE cleanup was done: (vi) transferred $5 \mathrm{~mL}$ of extract to a minicentrifuge tube containing $150 \mathrm{mg}$ anhydrous $\mathrm{MgSO}_{4}$ and $50 \mathrm{mg}$ PSA (per $1 \mathrm{ml}$ extract) and add $75 \mu \mathrm{L}$ of TPP solution, (vii) mixing the extract with the sorbent/desiccant for $30 \mathrm{~s}$, (viii) centrifuged at $3450 \mathrm{rcf}$ for $1 \mathrm{~min}$, (ix) transferred $2 \mathrm{~mL}$ of extract into an autosampler vial and evaporated the extract, (x) adding $1 \mathrm{~mL} \mathrm{MeCN}$ to the vial, (xi) and injecting $1 \mu \mathrm{L}$ of it to GC-MS analyser.

\section{Calibration}

Two different types of calibration curve were studied: matrix-matched calibration (MC) and solvent calibration (SC). Matrix-matched calibration solutions were prepared by mixing known volumes of the pesticide working solutions and the ISTD solution and filling up the volume with extracts of blank samples. 5 concentration levels of pesticides were applied for calibration: 0.05 , $0.5,1,5$ and $10 \mu \mathrm{gmL}^{-1}$. In solvent calibration set, solutions were prepared as above but using pure solvent for filling up the volume. $1 \mu \mathrm{l}$ of each concentration level were injected to GC-MS, starting with the lowest concentration level for two types of calibration standard mixes.

\section{Recovery studies}

Organic cucumber and tomato were used for the recovery experiments. $15 \mathrm{~g}$ homogenized blank sample was spiked before determination procedure by the addition of a mixture of standard pesticide solutions to give 0.1 and $1 \mathrm{mgkg}^{-1}$ of each compound. Spiking samples were left to stand overnight to allow pesticide absorption onto the sample. They were then prepared according to the sample preparation method described above.

\section{Validation studies}

The linearity of the method $\left(\mathrm{R}^{2}>0.991\right)$ was determined injecting $1 \mu \mathrm{L}$ of spiked blank matrix extracts $\left(0.05,0.5,1,5\right.$ and $\left.10 \mu \mathrm{g} \mathrm{mL}^{-1}\right)$ in triplicate. Linear calibration graphs were constructed by least-squares regression of concentration versus relative peak area of the calibration standards. The limit of detection (LOD) and limit of quantification (LOQ) were evaluated statistically as 3 and 10 times of, respectively, the standard deviation of the signal of blank solution for each pesticide. The analytical signals obtained for each of the spiked samples were quantified using SC and its corresponding MC, obtaining the calculated concentration from each calibration curve. Recoveries of spiked samples were calculated from Equation below:

$$
R \%=\frac{C_{\text {calculated }}}{C_{\text {spiked }}} \times 100
$$

Where $\mathrm{C}_{\text {calculared }}$ and $\mathrm{C}_{\text {spiked }}$ are estimated and spiked concentrations. To compare calibration techniques absolute percentage differences of mean recoveries that were calculated using each calibration equation were calculated. The aim of validation is to know if recovery results from spiked samples are different when the "calculated concentration" is estimated from matrixmatched calibration. A t-test was applied to data obtained in the recovery experiments to check if the mean value of recoveries differs statistically from $100 \%$ for $n-1=2$ degrees of freedom and a confidence level of $95 \%$. To assess the effect of spiked concentration on recovery values, we applied a two-sample t-test for each matrix.

\section{RESULTS AND DISCUSSION}

\section{Chromatographic determination using GC/MS-SIM}

Pesticides were identified according to retention time, a target ion and two qualifier ions. Quantitation was based on the peak area ratio of the target ion divided by that of internal standard (TPP) and compared to concentrations of calibration standard. Table 1 shows the pesticides studied with their target and qualifier ions used in SIM mode to analyze pesticide residues in Iranian cucumber and tomato. Figure 1 shows the GC-MS chromatograph for 19 pesticides in tomato matrix.

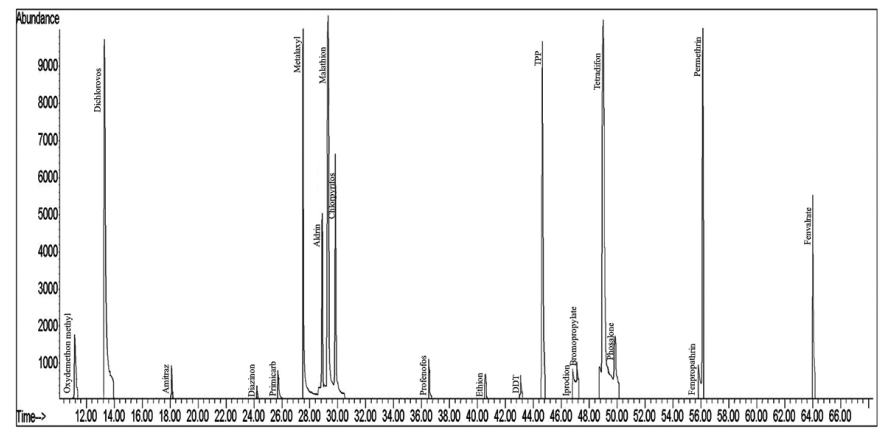

Figure 1. GC-MS chromatogram in selected ion monitoring mode for 19 pesticides in tomato matrix, spiked level was $5 \mathrm{mgKg}^{-1}$.

\section{Recovery studies}

The analytical signals of each spiked samples were quantified using matrix match and solvent calibrations. The recovery values of the spiked pesticides calculated from the $\mathrm{SC}$ were compared with the $\mathrm{MC}$ recoveries, which we assumed were more accurate. Figure 2 presents the absolute subtracted differences in calculated average recoveries in the solvent-only calibration versus the matrix-matched results for each pesticide and matrix (value falls below $15 \%$ are considered as negligible difference). As illustrated in figure 2 Aldrin and Malathion which showed insignificant matrix effects in tomato, demonstrated recovery differences below $15 \%$, but Metalaxyl, Oxydemethon methyl and Primicarb which have shown matrix effects in both matrixes have recovery differences $>15 \%$. As shown in figure 2 , significant matrix effect has been observed for most pesticides.

Recoveries obtained using matrix matched calibrations were between $75 \%$ and $115 \%$ in both matrixes. Table 2 and 3 show the recovery values in two concentration levels for cucumber and tomato respectively using matrix matched calibration.

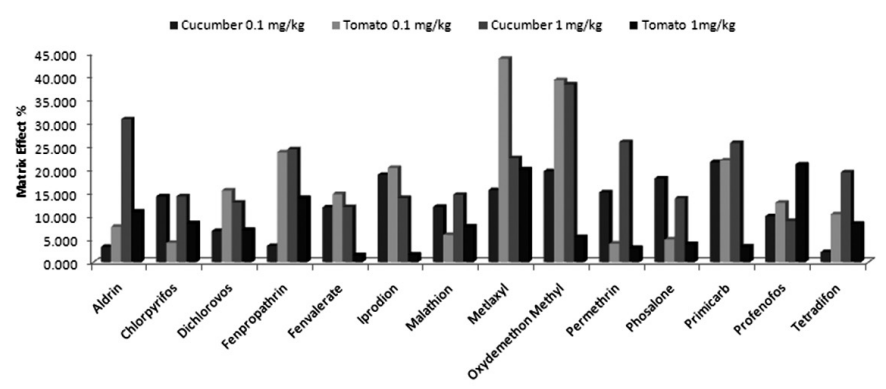

Figure 2. Absolute Subtracted differences in the calculated recoveries of each pesticide using the solvent (SC) and matrix matched (MC) calibration results for the cucumber and tomato matrixes.

\section{Method validation}

All the 19 pesticides could be detectable at $0.04 \mu \mathrm{gmL}^{-1}$ or even at lower level with the present method conditions used in this study. LOQs were lower than national maximum residue limit (MRL) for all pesticides. The coefficient of determination $\left(\mathrm{R}^{2}\right)$ of the calibration curves in matrix-matched was $\geq 0.991$ for all studied pesticides. The intra-day precision was examined with 5 repeated injections of two sample solutions containing the analytes at two concentration levels $\left(0.10\right.$ and $\left.0.25 \mu \mathrm{gmL}^{-1}\right)$ for each pesticide the RSDs were lower than $6.67 \%$ in all cases. Regression equation, limit of detection, limit of quantification, dynamic ranges, coefficient of determination, recoveries, and repeatability values are illustrated in Tables 2 and 3 for each pesticide in cucumber and tomato matrixes, respectively. Validation of matrix-matched calibration was performed from data obtained in the recovery study, as stated in the experimental section. A statistical test was applied to the mean of the recovery values for all 19 pesticides in cucumber and tomato matrixes to compare calculated recoveries with the $100 \%$ considering a probability $<5 \%$. When recoveries obtained with matrix match calibration were compared with 
$100 \%$ for all 19 pesticides in both matrixes, the P-value obtained was $>0.05$, which means recoveries estimated quantifying with matrix match calibration are not statistically different from $100 \%$ recovery. As an example, the $t$ test results for chlorpyrifos at two spiked levels in both matrixes are shown in table 4. As showed in table 4, recovery of chlorpyrifos at two spiked levels in both matrixes compared with $100 \%$ and in all cases $t$ is less than $t=4.3$, which means that the matrix-matched calibration yields an estimate of the sample concentration statistically similar to $100 \%$ of the spiked amount (Recovery does not differ of $100 \%$ ). A two-sample t-test was applied to evaluate the effect of concentration on recoveries. Statistical results showed for all pesticides, there is no statistical difference between calculated recoveries for two spiked levels in both matrixes. Results of two-sample t-test for chlorpyrifos are summarized in table 5. As table 5 shows $\mathrm{p}$ values are $>0.05$ which means QuEChERS sample preparation has the same recoveries at different concentrations and this method can be applied for routine analysis of real samples.

TABLE 1. Pesticides studied, their chemical class, retention time (Rt) and their target and qualifier ions used in SIM mode.

\begin{tabular}{|c|c|c|c|c|}
\hline No. & Pesticide & Chemical Class & $\mathrm{Rt}$ (min) & Monitored ions in SIM, $\mathrm{m} / \mathrm{z}^{*}$ \\
\hline 1 & Oxydemeton methyl & Organophosphate & 11.2 & $\mathbf{1 0 9}, 169$ \\
\hline 2 & Dichlorvos & Organophosphate & 13.3 & $109, \mathbf{1 8 5}$ \\
\hline 3 & Amitraz & Amidine & 18 & 162,147 \\
\hline 4 & Diazinon & Organophosphate & 24.2 & $\mathbf{3 0 4}, 137,179$ \\
\hline 5 & Primicarb & Carbamat & 25.8 & 166,238 \\
\hline 6 & Metalaxyl & Acylalanile & 27.9 & $\mathbf{1 3 2}, 206$ \\
\hline 7 & Aldrin & Organochlorine & 29.2 & 263,293 \\
\hline 8 & Malathion & OrganophosphaTE & 29.7 & $\mathbf{1 7 3}, 125$ \\
\hline 9 & Chlorpyrifos & Organophosphate & 30.2 & $199, \mathbf{1 9 7}, 314$ \\
\hline 10 & Profenofos & Organophosphate & 36.6 & 208, 338.9, 296.9 \\
\hline 11 & Ethion & Organophosphate & 40.9 & $\mathbf{2 3 1}, 135$ \\
\hline 12 & $4,4^{\prime}-\mathrm{DDT}$ & Organochlorine & 43.2 & 235,237 \\
\hline 13 & Triphenyl phosphate & - & 45.1 & $\mathbf{3 2 6}, 325,327$ \\
\hline 14 & Iprodione & Imidazole & 47 & $314, \mathbf{3 1 6}, 187$ \\
\hline 15 & Bromopropylate & Benzilate & 47.5 & $105, \mathbf{2 6 2}$ \\
\hline 16 & Fenpropathrin & Pyrethroid & 48.9 & $\mathbf{2 0 8}, 181,265$ \\
\hline 17 & Tetradifon & Diphenyl & 49.5 & 159,227 \\
\hline 18 & Phosalone & Organophosphate & 50.3 & $\mathbf{1 8 2}, 121$ \\
\hline 19 & Permethrin & Pyrethroid & 56 & $183, \mathbf{1 6 3}$ \\
\hline 20 & Fenvalerate & Pyrethroid & 64.4 & $\mathbf{1 8 1}, 167,152$ \\
\hline
\end{tabular}

${ }^{*}$ Target ions are printed in bold.

\section{Application to real samples}

To validate the efficiency of the method, 10 samples of each tomato and cucumber were analyzed. Both vegetables ( 20 samples) were taken from fresh market in Tehran. Analysis of real samples demonstrated the efficiency of this developed method which allowed the identification and quantification of pesticide present in the sample at below default Iranian MRL for tomato and cucumber.

\section{CONCLUSSION}

A simple, rapid and accurate method was developed to determine residues of pesticides in cucumber and tomato using matrix match calibration for the first time in Iran. This method using QuEChERS sample preparation and GCMS-SIM analysis showed a high sensitivity and confirmatory power necessary for the determination of pesticide residues at the levels required in Iran's MRL for cucumber and tomato. In this study two types of calibration were compared for quantitation of 19 pesticide residues in cucumber and tomato. Statistical studies revealed the efficiency of matrix match calibration for quantifying 19 fungicide and insecticide residues in cucumber and tomato. The proposed method not only allows the simultaneous determination and confirmation of pesticides of different classes with good recoveries and low detection limits but also eliminates matrix effects in quantitation of pesticide residues.

\section{ACKNOWLEDGMENT(S)}

This work was supported by grants of the project "monitoring of pesticide residue in fresh fruit and vegetables, 2011-2012". The authors gratefully acknowledge the financial support by "organization of the fruit and vegetable market of Tehran". 
TABLE 2. Regression equation, limit of detection (LOD), limit of quantification (LOQ), linear dynamic range (LDR), coefficient of determination ( $\mathrm{R}^{2}$ ), recoveries, repeatability (RSD) values for each pesticide in cucumber matrix.

\begin{tabular}{|c|c|c|c|c|c|c|c|c|c|c|}
\hline \multirow[b]{2}{*}{ NO. } & \multirow[b]{2}{*}{ Pesticides } & \multirow[b]{2}{*}{ Regression equation } & \multirow[b]{2}{*}{ LOD } & \multirow[b]{2}{*}{ LOQ } & \multirow[b]{2}{*}{ DLR } & \multirow[b]{2}{*}{$\mathrm{R}^{2}$} & \multicolumn{2}{|c|}{ Recovery, \% ( \pm RSD) ${ }^{*}$} & \multicolumn{2}{|c|}{ Repeatability, \% } \\
\hline & & & & & & & $1 \mathrm{mgkg}^{-1}$ & $0.1 \mathrm{mgkg}^{-1}$ & $\begin{array}{c}0.1 \\
\text { mgkg }^{-1}\end{array}$ & $\begin{array}{c}0.25 \\
\mathrm{mgkg}^{-1}\end{array}$ \\
\hline 1 & Aldrin & $y=6.863 x-1.306$ & 0.031 & 0.100 & $0.05-10$ & 0.999 & $109.00( \pm 0.13)$ & $114.83( \pm 3.54)$ & 6.51 & 3.72 \\
\hline 3 & Bromopropylate & $y=0.542 x+0.316$ & 0.032 & 0.120 & $0.05-10$ & 0.991 & $93.98( \pm 3.04)$ & $75.6( \pm 15.02)$ & 0.64 & 0.40 \\
\hline 4 & Chlorpyrifos & $y=0.883 x+0.802$ & 0.028 & 0.093 & $0.05-10$ & 0.998 & $98.80( \pm 1.28)$ & $112.94( \pm 0.74)$ & 0.91 & 2.00 \\
\hline 7 & Dichlorovos & $\mathrm{y}=5.005 \mathrm{x}-1.267$ & 0.010 & 0.033 & $0.05-10$ & 0.998 & $113.12( \pm 6.87)$ & $109.00( \pm 15.18)$ & 1.57 & 3.36 \\
\hline 8 & Ethion & $\mathrm{y}=32.991 \mathrm{x}-9.990$ & 0.016 & 0.053 & $0.05-10$ & 0.996 & $73.96( \pm 3.32)$ & $81.00( \pm 5.14)$ & 4.94 & 2.44 \\
\hline 9 & Fenpropathrin & $y=0.504 x+0.358$ & 0.017 & 0.057 & $0.05-10$ & 0.998 & $95.97( \pm 6.22)$ & $80.78( \pm 4.48)$ & 1.50 & 2.82 \\
\hline 10 & Fenvalerate & $y=1.316 x-0.108$ & 0.038 & 0.127 & $0.05-10$ & 0.999 & $110.64( \pm 3.50)$ & $110.64( \pm 3.50)$ & 1.09 & 1.23 \\
\hline 11 & Iprodion & $y=0.141 x+0.336$ & 0.015 & 0.050 & $0.05-10$ & 0.997 & $107.36( \pm 6.08)$ & $115.60( \pm 14.75)$ & 3.00 & 6.46 \\
\hline 15 & Permethrin & $y=2.401 x-0.920$ & 0.034 & 0.113 & $0.05-10$ & 0.999 & $105.84( \pm 7.26)$ & $113.81( \pm 6.34)$ & 3.94 & 4.69 \\
\hline 16 & Phosalone & $y=1.029 x-0.214$ & 0.045 & 0.150 & $0.05-10$ & 0.996 & $110.09( \pm 8.34)$ & $108.26( \pm 6.78)$ & 1.05 & 1.66 \\
\hline 17 & Pirimicarb & $y=45.401 x+0.364$ & 0.027 & 0.090 & $0.05-10$ & 0.999 & $103.00( \pm 0.34)$ & $118.86( \pm 5.96)$ & 1.97 & 1.82 \\
\hline 18 & Profenofos & $\mathrm{y}=1.219 \mathrm{x}+1.040$ & 0.026 & 0.087 & $0.05-10$ & 0.999 & $112.70( \pm 14.06)$ & $97.64( \pm 9.86)$ & 0.14 & 0.29 \\
\hline 19 & Tetradifon & $\mathrm{y}=21.382 \mathrm{x}-0.453$ & 0.044 & 0.133 & $0.05-10$ & 0.997 & $96.00( \pm 0.32)$ & $111.83( \pm 4.95)$ & 3.95 & 1.60 \\
\hline
\end{tabular}

*Average of thee replicates.

TABLE 3. Regression equation, limit of detection (LOD), limit of quantification (LOQ), linear dynamic range (LDR), coefficient of determination ( $\mathrm{R}^{2}$ ), recoveries, repeatability (RSD) values for each pesticide in tomato matrix.

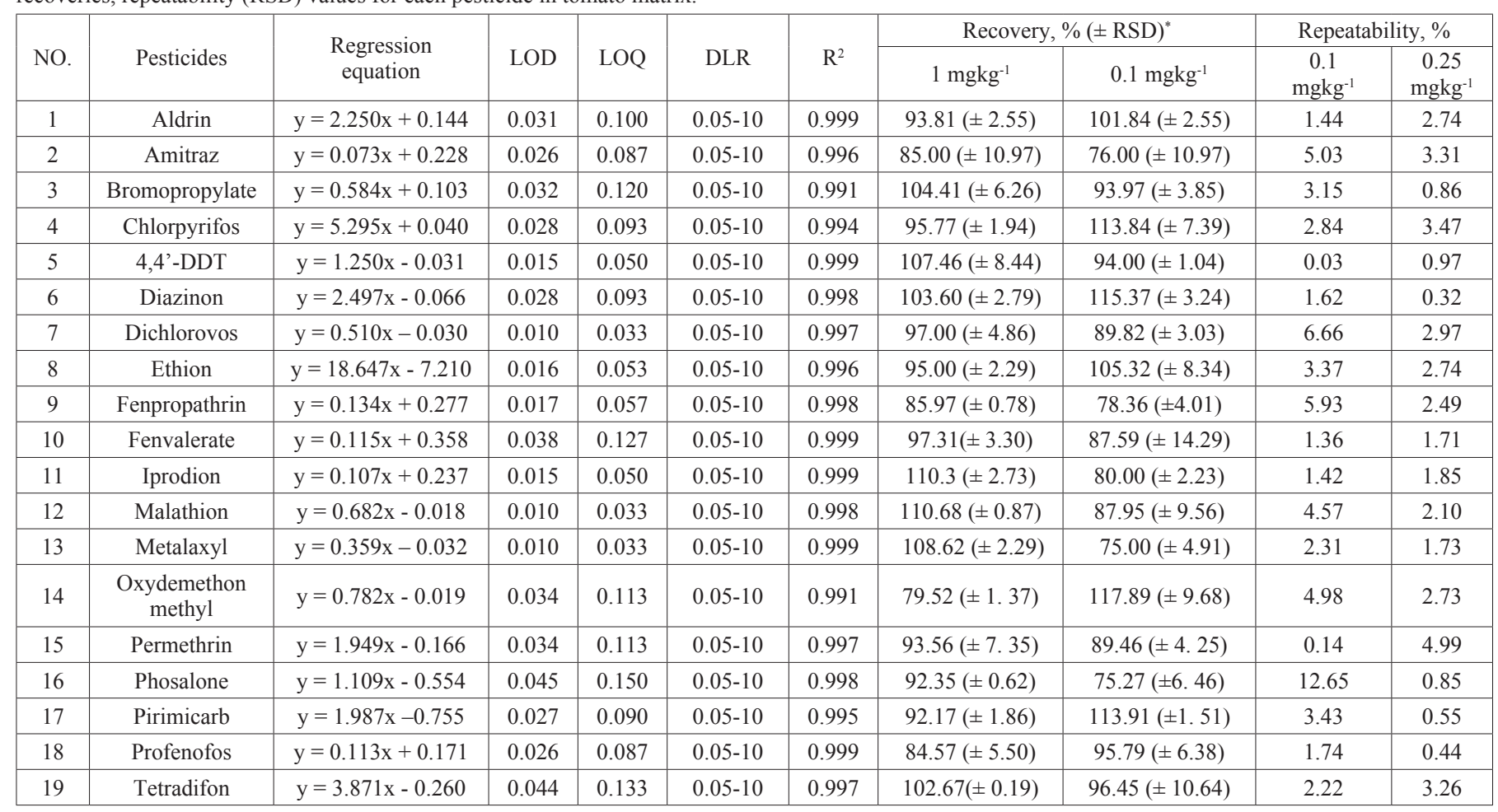

${ }^{*}$ Average of thee replicates. 
TABLE 4. t-test results for comparison of mean recovery with $100 \%$, obtained using matrix match calibration for quantifying chlorpyrifos in two spiked samples of cucumber and tomato.

\begin{tabular}{|c|c|c|c|c|}
\hline \multirow{2}{*}{ Statistics } & \multicolumn{2}{|c|}{ Tomato } & \multicolumn{2}{c|}{ Cucumber } \\
\cline { 2 - 5 } & $0.1 \mathrm{mgkg}^{-1}$ & $1 \mathrm{mgkg}^{-1}$ & $0.1 \mathrm{mgkg}^{-1}$ & 112.94 \\
\hline Recovery $^{*}$ & 113.89 & 95.77 & 11.49 & 98.80 \\
\hline StDev $^{* *}$ & 13.72 & 17.80 & 1.95 & -1.27 \\
\hline $\mathrm{t}_{\text {cal }}{ }^{* * *}$ & 1.75 & -0.41 & 0.191 & 0.242 \\
\hline $\mathrm{P}$ & 0.223 & 0.721 & \\
\hline
\end{tabular}

${ }^{*}$ Recovery values are average of three replicates

${ }^{* *}$ StDev.: standard deviation of recoveries

${ }^{* * * *} \mathrm{t}_{\text {cal }}:$ calculated $\mathrm{t}$ value $(\mathrm{P}<5 \%$ indicates significant differences between recoveries and $100 \%)$

TABLE 5. t-test results for comparison of mean recoveries of chlorpyrifos in two spiked samples of cucumber and tomato.

\begin{tabular}{|c|c|c|}
\hline Matrix type & $\mathrm{t}_{\text {cal }}{ }^{*}$ & $\mathrm{P}$ \\
\hline Cucumber & 2.12 & 0.10 \\
\hline Tomato & 1.39 & 0.24 \\
\hline
\end{tabular}

${ }^{*} \mathrm{t}_{\text {cal }}$ : calculated $\mathrm{t}$ value $(\mathrm{P}<0.05$ indicates significant differences between recoveries at two spiked levels).

\section{REFERENCES}

1. J. Tekel, J. Kovacicov'a, J. Chromatogr. A. 643, 291, (1993)

2. I.R. Pizzutti, A. de Kok, R. Zanella, M.B. Adaime, M. Hiemstra, C. Wickert, O.D. Prestes, J. Chromatogr. A.1142, 123, (2007)

3. A. Agüera, S. Lpez, A.R. Fernández-Alba, M. Contreras, J. Crespo, L. Piedra, J. Chromatogr. A. 1045, 125, (2004)

4. D. Ortelli, P. Edder, C. Corvi, Anal. Chim. Acta 520, 33 (2004)

5. K. Banerjee, D.P. Oulkar, S. Dasgupta, S.B. Patil, S.H. Patil, R. Savant, P.G. Adsule, J. Chromatogr. A. 1173, 98, (2007)

6. K. Gramby, J.H. Andersen, H.B. Christensen, Anal. Chim. Acta 520, 165, (2004)

7. F. Hernández, O.J. Pozo, J.V. Sancho, L. Bijlsma, M. Barreda, E. Pitarch, J. Chromatogr. A. 1109, 242, (2006)

8. C. Gíez, W.A. Traag, P. Zommer, P. Marinero, J. Atienza, J. Chromatogr. A. 1131, 11, (2006)

9. G. Pang, Y. Cao J. Zhang, C. Fan, Y. Liu, X. Li, G. Jia, Z. Li, Wu y. T. Guo, J. Chromatogr. A. 1125, 1, (2006)

10. O. Shimelis, Y. Yang, K. Stenerson, T. Kaneko, M. Ye, J. Chromatogr. A. 1165, 18, (2007)

11. B. Gilbert-López, J. F. García-Reyes, A. Molina-Díaz, Talanta 79, 109, (2009)

12. M. Anastassiades, S.J. Lehotay D. Štajnbaher F. J. Schenck, J. AOAC Int. 86, 412, (2003)

13. P. Payá, M. Anastassiades, D .Mack, I .Sigalova, B. Tasdelen, J. Oliva, A. Barba, Anal. Bioanal. Chem. 389, 1697, (2007)

14. M. Anastassiades, K. Maštovská, S. J. Lehotay, J. Chromatogr. A. 1015, 63, (2003)

15. A. Morales, I. Ruiz, J. Oliva, A. Barba, J. Environ. Sci. Health, Part B 46, 525, (2011)

16. J. Hernández-Borges, J. Cabrera Cabrera, M.A. Rodríguez-Delgado, E.M. Hernández-Suárez, V. Galán Saúco, Food Chem. 113, 313, (2009)

17. C. Lesueur, P. Knittl, M. Gartner, A. Mentler, M. Fuerhacker, Food Control 19, 906, (2008)

18. R. Húšková, E. Matisová, S. Hrouzková, L'. Švorc, J. Chromatogr. A. 1216, 6326, (2009)

19. L. Chen, X.S. Li, Z.Q. Wang, CP. Pan, R.C. Jin, Ecotoxical. Environ. Saf. 73, 73, (2010)

20. T.D. Nguyen, J.E. Yu, D.M. Lee, G.H. Lee, Food Chem. 110, 207, (2008)

21. S.J. Lehotay, K. Mastovska, S.J. Yun, J. AOAC Int. 88, 630, (2005)

22. C. Przybylski, C. Segard, J. Sep. Sci. 32, 1858, (2009)

23. X.B. Yang, G. Ying, G. Rai, S. Kookana, J. Environ. Sci. Health, Part B 45, 152, (2010)

24. S.C. Cunha, S.J. Lehotay, K. Mastovska, J.O. Fernandes, M.B.P.P. Oliveira, J. Sep. Sci. 30, 620, (2007)

25. J. Keegan, M. Whelan, M. Danaher, S. Crooks. R. Sayers, A. Anastasio, C. Elliott, D. Bron, A. Furey, R. O'Kennedy, Anal. Chim. Acta 654, 111, (2009)
26. S. H. G. Brondi, A. N. De Macedo, G. B. de Souza, A. R. A. Nogueira, J. Environ. Sci. Health, Part B 46, 671, (2011)

27. T.D. Nguyen, K.J. Lee, M.H. Lee, G.H. Lee, Microchem. J. 95, 43, (2010)

28. S. Walorczyk, B. Gnusowski, J. Chromatogr. A.1216, 6522, (2009)

29. Food and Drug Administration. Pesticide Analytical Manual Volume I: Multiresidue Methods, 3rd ed. US Department of Health Human Services, Washington, DC. 1999

30. M. A. Luke, J.E. Froberg, H. T. Masumoto, J. AOAC Int. 58, 1020, (1975)

31. W. Specht, M. Tilkes, Fresenius J. Anal. Chem. 301, 300 (1980)

32. S. M. Lee, M. L. Papathakis, C. F. Hsiao-Ming, J. E. Carr, Fresenius J. Anal. Chem. 339, 376, (1991)

33. A. Andersson, H. Pálsheden, J. Fresenius, Anal. Chem. 339, 365, (1991)

34. J. Cook, M. P. Beckett, B. Reliford, W. Hammock, M. Engel, J. AOAC Int. 82, 1419, (1999)

35. P. Stefanelli, A. Santilio, L. Cataldi, R. Dommarco, J. Environ. Sci. Health, Part B 44, 350, (2009)

36. J. Fillion, F. Sauvé, J. Selwyn, J. AOAC Int. 83, 698, (2000)

37. R. S. Sheridan, J. R. Meola, J. AOAC Int. 82, 982, (1991)

38. R.S. Da Silva, C.P. Da silva, S. Navickiene, J. Environ. Sci. Health, Part $B \mathbf{4 5}, \mathbf{5 8 9},(2010)$

39. H. G. Mol, R. C. van Dam, O. M. Steijger, J. Chromatogr. A. 1015, 119 (2003)

40. J. Klein, L. Alder, J. AOAC Int. 86, 1015, (2003)

41. B. Albero, C. Sa' nchez-Brunete, J. L. Tadeo, Talanta 66, 917, (2005)

42. D. A. Souza, F. M. Lanças, J. Environ. Sci. Health, Part B 38, 417, (2003)

43. M. D. Herno, A. Agu" era, A. R. Ferna'ndez-Alba, L. Piedra, M. Contreras, Analyst 126, 46, (2001)

44. M. Araoud, W. Douki, A. Rhim, M. F. Najjar, N. Gazzah, J. Environ Sci. Health, Part B 42, 179, (2007). 